\title{
"Daqui uns tempos é tudo informática": análise de uma experiência nos Anos Iniciais da EJA
}

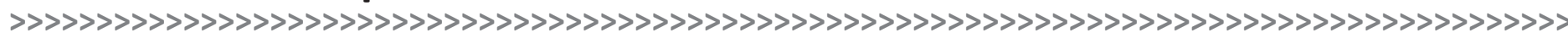

Daiane Martins Bocasanta* Tásia Fernanda Wisch**

\begin{abstract}
Resumo:
Esse trabalho analisa uma experiência pedagógica ocorrida numa escola pública federal, com uma turma de Anos Iniciais da Educação de Jovens e Adultos. Essa experiência surgiu a partir da necessidade que o grupo de estudantes demonstrou, de aprender mais sobre o uso de tecnologias digitais. O referencial teórico que embasa o estudo situa-se nas teorizações pós-estruturalistas. Em aulas semanais de informática foi possível introduzir os alunos ao uso do computador, com a exploração de diferentes recursos. Durante todo ano letivo, foi possível observar o crescente interesse dos alunos pelas aulas, bem como, grandes avanços em suas aprendizagens. Suas falas e a qualidade de suas produções individuais ao final do período, evidenciaram que a prática pedagógica organizada foi importante para que os alunos se sentissem incluídos no mundo atual, que é fortemente ligado à tecnociência.
\end{abstract}

\section{Palavras-chave:}

Tecnociência. Educação de Jovens e Adultos. Práticas pedagógicas.

\begin{abstract}
:
This work analyzes a pedagogical experience that took place in a federal public school, with a class of Early Years of Education of Youth and Adults. This experience emerged from the need that the group of students demonstrated in learning more about the digital technologies usage. The theoretical reference of the study is based on post-structuralist theories. With weekly informatics classes, it was possible to introduce students to computer usage, exploring different resources. Throughout the school year, it was possible to observe the increasing interest in the classes, as well as great progress in their learning. Their speeches and the quality of individual productions at the end of the period showed that an organized pedagogical practice was important for students to feel included in today's world, which is strongly linked to technoscience.
\end{abstract}

\section{Keywords:}

Technoscience. Youth and Adult Education. Pedagogical practices.

\section{Introdução}

Esse trabalho apresenta o exame de uma experiência ocorrida numa turma de Alfabetização e Pós-Alfabetização da Educação de Jovens e Adultos de uma escola pública de Porto Alegre-RS durante o ano de 2016. Tal experiência consistiu na organização, por
* > Pedagoga, Mestre em Educação e Doutora em Educação pela Universidade do Vale do Rio dos Sinos. Professora dos Anos Iniciais do Departamento de Humanidades do Colégio de Aplicação da UFRGS E-mail: daianebocasanta@gmail.com

** > Mestre em Educação pela Universidade Federal de Santa Maria. Professora de Educação Especial do Departamento de Humanidades do Colégio de Aplicação da UFRGS. E-mail: tasiafw@gmail.com 
parte da professora titular da turma e de uma das educadoras especiais da escola acompanhada de sua equipe de bolsistas, de aulas semanais de informática, inclusive com o uso da plataforma Moodle. Essas aulas surgiram a partir da necessidade demonstrada pelos alunos de estudarem mais sobre o uso de computadores, como - conforme mostramos adiante - forma de sentirem-se incluídos em um mundo eivado de novidades tecnológicas. Do mesmo modo as atividades também se originaram da curiosidade das professoras, que buscavam pesquisar como os alunos de EJA se posicionam e como são posicionados em relação aos conhecimentos tecnocientíficos. A frase que utilizamos para compor o título desse estudo foi proferida por um dos alunos da turma, um senhor de 69 anos:

Por isso seria muito importante se as escolas ensinassem nós a computação. Aprender mais... embora a gente já tá velho, mas a gente nunca esquece um pensamento da pessoa, em melhorar a situação da pessoa, né? E melhorar a situação da pessoa, tu estudando. Tu vai pra sala de aula, tu vai estudar, tu vai fazer os graus que eles querem, tu vai subindo, porque tu tá interessado naquilo, tu botou na tua cabeça que tu vai aprender informática, o... tem que ser... não adianta, se a pessoa não se interessar não vai conseguir vencer. Daqui uns tempos é tudo informática, não adianta nada. $\mathrm{O}$ trabalho pra gente é informática (grifo nosso).

Para o estudante da turma de Anos Iniciais da EJA, a idade, apesar de avançada, não seria um empecilho para aprender a usar o computador. Para ele, "daqui uns tempos é tudo informática" e desse modo, aprender a lidar com a máquina seria o único caminho para se sentir incluído. O caso desse aluno não era isolado. Nas falas de todos havia presente a vontade de dominar ferramentas tecnológicas. Diziam estar preocupados e até mesmo envergonhados por precisarem de ajuda inclusive no manuseio do caixa eletrônico no banco. De acordo com a turma que participou do trabalho aqui apresentado, a tecnologia estaria em evolução constante, mudando o mundo e quiçá eles mesmos, conforme a fala que aqui destacamos: "A tecnologia cada vez tá subindo mais. Coisas diferentes que a gente nem imagina já tem. Eu queria que eles fizessem uma coisa: renovar nós depois de velho. Eles fazem de tudo que é coisa aí... Fazer de mim um robozinho aí!”. Expressavam também o quanto pensavam ser necessário se atualizar para ajudar as próximas gerações de suas famílias: "E nós sempre queremos ensinar nossas crianças, nossa juventude a aprender bastante porque o dia de amanhã será mais, cada vez mais difícil. Quem não tem estudo já era. Quem puder pagar uma graduação... porque vai ficar mais difícil”.

De certo modo, as falas dos alunos que inserimos nessa escrita, dizem respeito ao que viemos percebendo como uma naturalização das tecnologias (BENSAUDE-VINCENT, 2013, p. 175). A tecnociência, como argumenta Bensaude-Vincent (2013), desestabiliza crenças arraigadas e por isso, fomenta debates. "O questionamento da tecnociência a propósito, se confronta sem cessar com o já famoso conceito: 'Não podemos parar o progresso'. [...] Os discursos dos promotores das inovações tecnológicas alimentam com efeito, a crença num determinismo tecnológico orientado num sentido único, a 'flecha do progresso', à qual nada pode se subtrair" (BENSAUDE-VINCENT, 2013).

A tecnociência não seria caracterizada apenas pela inversão das prioridades entre ciência e técnica, como poderíamos presumir, mas pela “[...] entrada em cena de políticas mais de mercado no mundo da pesquisa científica e tecnológica" (BENSAUDE-VINCENT, 2013, p. 220). Assim, a tecnociência não se trataria de uma mudança de "paradigma" ou de uma "nova era" de reaproximação da ciência com a sociedade. Mais do que isso, a tecnociência constituiria, para Bensaude-Vincent (2013, p. 220), um processo que embaralha diversas histórias. Acompanhando a autora (BENSAUDE-VINCENT, 2013, p. 220), podemos dizer que esse processo é caracterizado por três traços principais a saber: 
“O Primeiro traço é um processo de "engrenagem” em que se solidariza diversos setores de atividades - como a ciência, a indústria, a agricultura, a economia, a política - desconsiderando suas reivindicações de autonomia" (BENSAUDE-VINCENT, 2013, p. 220-221). Desse modo, não haveria atividade de pesquisa "livre", com um fim em si mesma, tendo em vista que a imagem da engrenagem nos remete a interdependência. Do mesmo modo, supor que a ciência e técnica estariam subordinadas às leis de mercado seria um reducionismo. "Pede-se à ciência que 'produza' conhecimentos e ela passa cada vez mais a parecer uma atividade de administração, enquanto a gestão das empresas ou da saúde pública tornam-se cada vez mais um assunto científico" (BENSAUDE-VINCENT, 2013, p. 221).

No caso da educação escolarizada, essa ideia nos leva a refletir que não podemos falar da tecnologia como algo a serviço da educação, mas como algo que deve estar imbricado nos processos educativos. A educação se beneficia da tecnologia, da informática, mas também é parte importante e imprescindível para o avanço desses processos.

Seguindo Michel Foucault, a autora argumenta que o segundo traço mostra que a tecnociência visa transformar todas coisas em dispositivos.

\begin{abstract}
Nos anos de 1970, Michel Foucault descreveu o processo histórico do poder atuados por dispositivos técnicos que desafiam a cisão entre a zona do político e a zona do privado, do 'livre'. Esses dispositivos ou normas que passam para o interior do corpo fazem com que o político esteja por toda parte e em lugar algum ao mesmo tempo. Hoje, os 'tijolos' elementares da matéria e do ser vivo são transformados em dispositivos que devem supervisionar a bioquímica dos corpos dos indivíduos do mesmo modo como o corpo social. Tudo está potencialmente à disposição’ de um sujeito cada vez mais acorrentado a essas engrenagens deslocalizadas (BENSAUDE-VINCENT, 2013, p. 221).
\end{abstract}

Esses dispositivos, agem através da condução das condutas dos indivíduos, pela regulação de seus desejos, pela direção de seus interesses. Dispositivos seriam conjuntos heterogêneos que contemplariam "[...] discursos, instituições, organizações arquitetônicas, decisões regulamentares, leis, medidas administrativas, enunciados científicos, proposições filosóficas, morais e filantrópicas" (FOUCAULT, 2008, p. 244). Assim, entendemos que a vontade de aprender mais sobre o uso dos computadores e o entendimento expressado pelos estudantes de que "daqui uns tempos é tudo informática" faz parte da captura de tudo e de todos por um dispositivo que aqui optamos por nomear como dispositivo de tecnocientificidade (BOCASANTA, 2013). Os alunos que participaram da experiência aqui escrutinada, percebem, através dos programas de televisão e propagandas que assistem, das imagens veiculadas nos jornais, das conversas de corredor, daquilo que observam seus filhos e netos fazerem com seus artefatos digitais, das conversas de corredor nos seus locais de trabalho, etc., que seus conhecimentos são insuficientes para sentirem-se de fato parte desse mundo que hoje se descortina a nossa frente. Assim de forma análoga ao que foi evidenciado por Bocasanta, Wanderer e Knijnik (2016, p. 88), a respeito de estudantes de EJA, ao mesmo tempo em que são entusiastas da ciência e da tecnologia como promotoras de progresso, visando "um mundo melhor", "[...] os sujeitos da pesquisa entendem o quanto não fazer parte do seleto grupo que consegue se sobressair frente aos conhecimentos num cenário de rápidas (e por que não dizer grandiosas) mudanças pode ser doloroso". E todos são conclamados a fazer parte desse mundo. Todos querem se sentir incluídos. E ao falarmos em inclusão, aqui, não nos referimos apenas ao aprendizado para o uso das tecnologias. Nossa tentativa é trazer à tona o debate em torno da inclusão de todos os indivíduos nas discussões acerca de escolhas no campo da tecnociência que lhes afetam diretamente. 
O terceiro traço estabelecido por Bensaude-Vincent (2013, p. 221) diz respeito ao caráter globalizante da tecnociência, que envolve tudo e não deixa espaço para a exterioridade. Para a autora, nem mesmo as humanidades, que poderiam fazer o “[...] contraponto a essa empresa cada vez mais homogênea do tecnocientífico, não estão no exterior disso tudo. As próprias ciências humanas estão 'enroladas' no processo de experimentação social, chamadas a apresentar dispositivos de avaliação tecnológica, de participação". Esse último traço apresentado por Bensaude-Vincent (2013) nos leva a crer que, emaranhados nas tramas da tecnociência, não poderíamos fazer nada a não ser nos render ao seu reinado. No entanto, como a autora mesmo argumenta, isso não significaria a priori que não haveria lugar para a resistência, mas que a resistência a esse processo não poderia se dar de fora, a partir de um ponto fixo que possa se mover. Nesse sentido, ainda que houvesse a pretensão de fugirmos de um trabalho de sala de aula que fosse no mesmo sentido para o qual nos empurra o dispositivo da tecnocientifidade, como uma forma de resistência, em especial a todo um mercado e uma lógica que lhe é subjacente, excluindo alguns e privilegiando outros, provavelmente essa seria uma pretensão inócua. Nesse ínterim, nos questionamos: como controlar esses processos? Onde encontramos o controle? De acordo com a autora, qualquer resposta a essas perguntas, nesse momento, seria meramente experimental, ou seja, poderia - ou não - dar certo.

Refletindo a esse respeito, nossa opção política enquanto educadoras foi a de proporcionar aos nossos estudantes da Educação de Jovens e Adultos a introdução a instrumentalização no uso de ferramentas tecnológicas, como forma de inclusão nos debates políticos atuais e consequentemente na participação na sociedade.

\section{Objetivos}

O objetivo geral do trabalho pedagógico aqui apresentado e examinado foi desenvolver aulas de informática semanais, para um grupo de estudantes de uma turma de Anos Iniciais da EJA, como forma de instrumentalização para o uso de computadores e inserção em discussões mais amplas a respeito da tecnociência. Tal objetivo desdobrou-se nos seguintes objetivos específicos, entre outros: 1) aprender a ligar e desligar o computador; 2) utilizar o site Scala para construção de diversos tipos de produções textuais; 3) realizar atividades pedagógicas na plataforma Moodle; 4) explorar jogos pedagógicos na $W e b$; 5) debater o caráter pervasivo da tecnociência na vida de todos; 6) conhecer diferentes ferramentas de trabalho, como Word, PowerPoint, Paint, Calculadora, navegadores de internet, etc.

$1>$ Tradução nossa. No original: [...] debemos recordar que para Foucault pensar no es un buen pensar o un pensar bien; no se trata de pensar correctamente, pues su interés tampoco es el conocimiento: pensar no es conocer, el pensamiento no está em la dirección del conocimiento, la investigación foucaultiana no busca producir conocimiento, no se trata de una investigación científica. De la misma manera, la actividad de enseñanza del profesor Foucault no está en la línea de a transmisión de conocimientos, pero tampoco en la dirección de producir aprendizajes. Una y otra implican unos objetivos previos definidos en función del sujeto que aprende.

\section{Metodologia}

Ao falar sobre metodologia de pesquisa a partir de Foucault, Carlos Noguera (2009, p. 25) nos alerta que:

[...] devemos recordar que para Foucault pensar não é um bom pensar ou pensar bem; não se trata de pensar corretamente, pois seu interesse tampouco é o conhecimento: pensar não é conhecer, o pensamento não está na direção do conhecimento, a investigação foucaultiana não busca produzir conhecimento, não se trata de investigação científica. Da mesma maneira, a atividade de ensino do professor Foucault não está na linha de transmissão de conhecimentos, nem tampouco na direção de produzir aprendizagens. Uma e outra implicam os objetivos prévios definidos em função do sujeito que aprende. ${ }^{1}$ 
Usar uma noção metodológica foucaultiana, como por exemplo, a governamentalidade como uma ferramenta para pensar, faz com que ela se constitua como um instrumento “[...] para provocar, para tensionar, para incitar o pensamento: pensar de outro modo, pensar o impensado antes que conhecer ou reproduzir o já sabido"2 (NOGUERA, 2009, p. 25). Desse modo, o que queremos dizer não é que trazer a informática para o currículo escolar da EJA seja algo novo ou inusitado. Autores como Canarin (2013), Amparo (2015) e Bendineli (2015) já investigaram a produtividade desse tipo de trabalho para essa clientela. Não queremos dizer também, que não queríamos ensinar nada aos sujeitos. O que queremos demarcar é que, apoiadas em Foucault, não tínhamos um ponto de chegada pré-definido quando iniciamos esse trabalho junto a turma de Alfabetização e Pós-Alfabetização que participou da experiência aqui relatada. Queríamos instrumentalizar nossos alunos para viver nesse mundo eivado de tecnociência, mas acima de tudo, queríamos colocá-los a pensar sobre o mundo em que vivemos. Podemos por fim dizer, que, essa experiência, que a seguir descrevemos não colocou apenas os alunos a pensar. Ela propiciou que também nós, docentes, pudéssemos tensionar e questionar o que já sabíamos de antemão - ou o que achávamos que sabíamos - sobre o que o grupo de estudantes atendidos poderiam produzir em aulas de informática.

\section{Do chão da sala de aula}

No início do ano letivo, a professora titular da turma de Anos Iniciais da EJA realizou um diagnóstico inicial da turma, em que verificou que os alunos tinham necessidade/ vontade de aprender mais sobre o uso de ferramentas tecnológicas. A turma em questão era composta por sete alunos - seis do sexo masculino e uma do sexo feminino -, com idades entre 33 e 68 anos. Entre esses alunos, quatro estavam em fase inicial de alfabetização e três já dominavam, ainda que de forma precária, a leitura e a escrita. No segundo semestre, com a evasão da única aluna mulher do grupo, o avanço de dois alunos para a turma correspondente aos Anos Finais do Ensino Fundamental, e a entrada de quatro novos alunos, a turma ficou composta por oito alunos, com idades entre 42 e 68 anos. Dentre esses alunos duas eram do sexo feminino e os demais do sexo masculino. Do total de alunos do segundo semestre, quatro alunos estavam em fase de alfabetização e quatro eram alfabetizados. Cabe mencionar que a turma em questão foi criada em 2014, com o objetivo de atender, em especial, a demanda de escolarização de funcionários da universidade a qual a escola é ligada, mas também da comunidade em geral. As ocupações dos estudantes fora da escola eram bastante variadas: porteiros, zeladores, aposentados, donas-de-casa, auxiliares de limpeza, lavadores de carro, jardineiros, etc. Além disso, é importante destacar que vários alunos possuíam condições de saúde que marcavam suas trajetórias pessoais e estudantis, tais como surdez, problemas de coluna, um aluno era transplantado, etc. As aulas da turma ocorreram no horário vespertino, de segunda-feira a sexta-feira, das $16 \mathrm{~h}$ às $19 \mathrm{~h}$.

Dado esse contexto, a partir de uma conversa entre a professora titular da turma e a educadora especial da escola, foram estruturadas aulas semanais no laboratório de informática da escola. A inserção da educação especial na turma de Alfabetização e Pós-Alfabetização teve como premissa acompanhar estudantes com indicativos de deficiência intelectual e surdez senil. Para tanto consolidou-se uma parceria entre a professora regente e a educadora especial. Ao longo das atividades desenvolvidas os relatos dos estudantes mencionavam a importância da alfabetização e o desejo em aprenderem a usar o computador.

Buscando articular e incentivar ambas aprendizagens propusemos aos estudantes o uso de um software denominado Scala. Este software é um produto desenvolvido a
$2>$ Tradução nossa. No original: [...] para provocar, para tensionar, para incitar o pensamiento: pensar de otro modo, pensar lo impensado antes de conocer o reproducir lo ya sabido. 
partir dos estudos e pesquisas do grupo TEIAS ${ }^{3}$ (Núcleo de Pesquisa de Tecnologias em Educação para Inclusão e Aprendizagem em Sociedade), da UFRGS. Este grupo tem se debruçado a estudar e desenvolver tecnologias assistivas - TAs para pessoas com autismo. Conforme Bez e Passerino (2015, p. 18-19),

O Scala é mais do que uma aplicação, é um sistema que engloba estratégias, metodologias e investigações que apoiam os processos inclusivos na nossa sociedade, resultado dos estudos e das pesquisas do Grupo Teias, que vem se dedicando sistematicamente ao ensino, à extensão e à pesquisa sobre a tecnologia, a linguagem e a comunicação de pessoas com deficiência, produzindo conhecimentos e atuando na formação qualificada de pesquisadores e professores, visando ao uso crítico e reflexivo das tecnologias em processos inclusivos e às relações homem-sociedade, com ênfase na aprendizagem ao longo da vida.

Fundamentadas pelos estudos do grupo Teias, pudemos identificar que as práticas docentes utilizando o software podem se constituir em uma importante ferramenta mediadora no processo de construção de conhecimentos.

Para tanto, ao longo do semestre nos propusemos a utilizar o Scala como estratégia metodológica de construção narrativas visuais, pois volta-se especificamente ao letramento e produção de histórias. Os estudos do grupo Teias elucidam que o uso de histórias narradas permite aos estudantes a aproximação entre os contextos vividos e situações imaginativas. Em termos práticos, essas premissas foram pautas das aulas de informática desenvolvidas com os estudantes da turma de Alfabetização e Pós-Alfabetização. Com auxílio, os alunos envolvidos foram desafiados e produzirem narrativas visuais contextualizadas com as temáticas trabalhadas em sala de aula bem como a articulação com situações cotidianas.

Posto isso, o desafio de usar uma máquina, nunca antes explorada, veio acompanhada dos conhecimentos prévios necessários para a realização da atividade. Portanto, mesmo com dificuldades em manusear o mouse ou encontrar imagens, cada um, era capaz de criar um contexto narrativo, com imagens e situações específicas.

Dentre as diferentes atividades realizadas no site Scala, destacamos duas. A primeira, ocorrida durante o desenvolvimento de um projeto sobre alimentação saudável, consistiu em propormos aos alunos que montassem, utilizando cenários e imagens variadas mesas com os alimentos que ingeriam durante um dia inteiro, separado por cada refeição que faziam (café da manhã, almoço, lanche da tarde e jantar). Após a montagem dos quadros, os alunos foram incentivados a escreverem os nomes dos alimentos que haviam selecionado. Essa atividade, que ocupou em torno de três aulas foi utilizada posteriormente para a discussão acerca das escolhas alimentares da turma, visando a adoção de hábitos mais saudáveis. Durante o processo, o grupo demonstrou dificuldades, mas muita criatividade e afinco.

A outra atividade consistiu na pesquisa e seleção de ditados gauchescos na internet para a construção de pranchas individuais com a interpretação gráfica daquilo que tinham pesquisado. Essa proposta, além de desenvolver habilidades para pesquisa em sites, proporcionou uma outra forma de trabalhar interpretação textual com a turma. Os alunos mostraram-se entusiasmados, reconhecendo na pesquisa alguns ditados populares gauchescos que seus pais e avós utilizavam quando eles eram crianças. Em suas narrativas visuais, pareciam se divertir com a escolha das imagens que comporiam suas interpretações. Ao final da tarefa, todos tinham a seu modo, atingido os objetivos propostos e sentiam-

3 > http://www.ufrgs.br/teias/sobre. Acesso em: 22 nov. 2018. se orgulhosos de suas produções, mostrando aos demais o que haviam conseguido fazer. Aqui estão alguns exemplos de produções dos alunos: 
Figura 1 - Atividade do Aluno 1

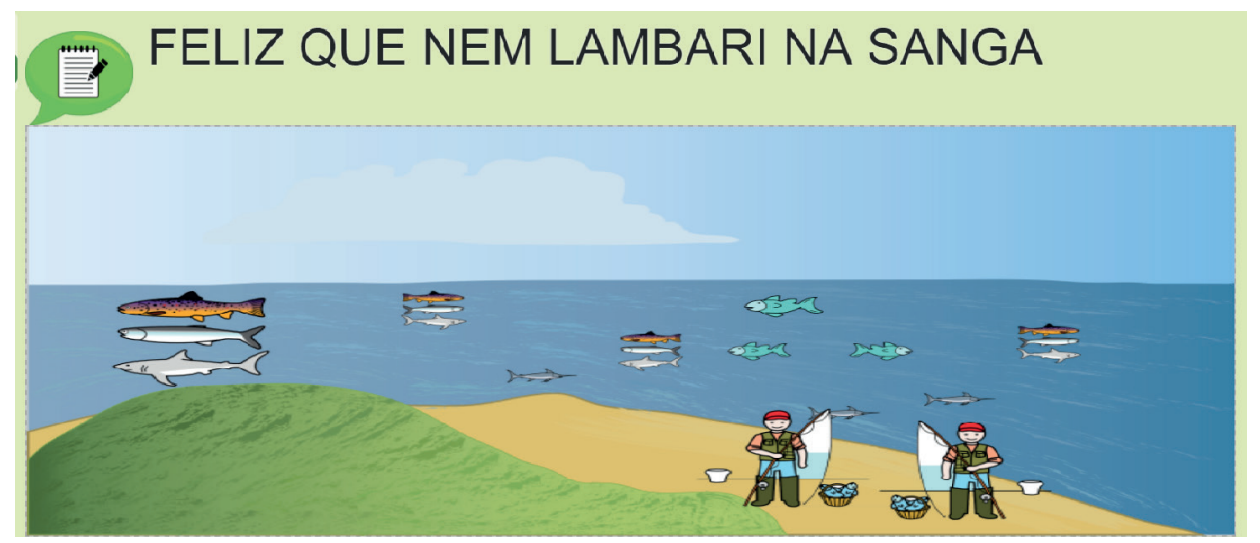

Fonte: Dados da Pesquisa, 2016.

Figura 2 - Atividade do Aluno 2

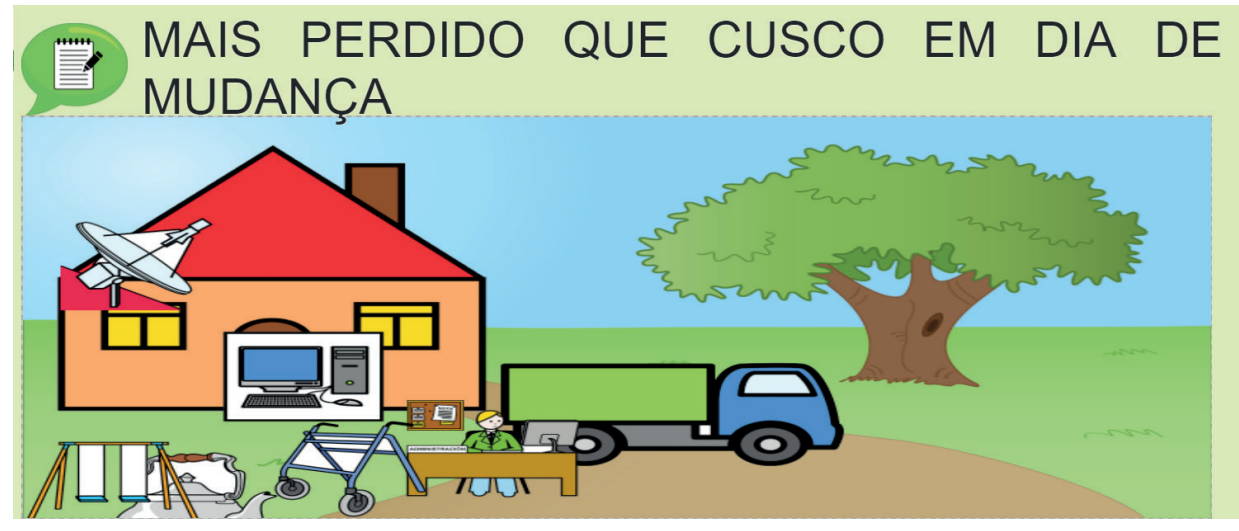

Fonte: Dados da Pesquisa, 2016.

A partir do interesse e dedicação às aulas de informática demonstrados pelos estudantes ao longo do primeiro semestre, resolvemos dar continuidade ao trabalho. Ao longo do período, além da exploração do Scala, abrimos uma turma na plataforma Moodle para a realização de atividades. Ainda que essa plataforma tenha sido concebida como uma ferramenta para uso EAD (Educação à Distância), na experiência em questão, ela foi adotada como uma estratégia pedagógica presencial. Isso deveu-se a diversos fatores: nem todos alunos da turma tinham acesso a computadores fora da escola, nem todos estavam alfabetizados, o que demandaria ajuda para a leitura das ordens das atividades e para sua realização e principalmente porque a maioria ainda estava tendo seus primeiros contatos com a informática e necessitavam auxílio individualizado.

O primeiro desafio para o uso da plataforma ocorreu quando pedimos aos alunos que trouxessem para a aula o número de sua matrícula e senha para acesso ao portal da universidade da qual a escola faz parte. Por em sua maioria, serem funcionários e por terem, através desse portal acesso a muitas informações pessoais, como controle de processos e de avaliações funcionais, bem como, é através do portal que podem participar de votações, como por exemplo a escolha do reitor, em nosso entendimento, os alunos que atuam na universidade deveriam ter esses dados. No entanto, apenas um dos estudantes do grupo tinha conhecimento de sua senha de acesso, ainda que nunca tivesse utilizado o portal sem o intermédio de algum colega. Foi, portanto, necessário entrar em contato com o setor de informática da instituição, que enviou um técnico à escola para que esse registrasse logins, e-mails e senhas de acesso para o grupo. 
Após esse início, que foi bastante conturbado, os alunos puderam construir seus perfis na sala de aula aberta para eles na plataforma Moodle.

Ao longo do semestre, muitas atividades foram realizadas com o auxílio da plataforma. As primeiras tarefas dos estudantes foram mais exploratórias. Assim, inserimos jogos pedagógicos na plataforma, bem como, links para os vídeos que já haviam sido trabalhados em sala de aula, para que os sujeitos pudessem acessar novamente. Após algumas aulas, passamos a inserir atividades relativas às aulas, através de fóruns, diários e construção de mapas conceituais coletivos. Observamos que essas tarefas foram produtivas tanto para aqueles alunos que já estavam mais adiantados em seu processo de alfabetização, quanto para os que estavam iniciando o processo. Numa das propostas, por exemplo, em que foi solicitado que os alunos registrassem em diário seus progressos na EJA, foi possível ler os seguintes relatos:

Então estou aprendendo mais ou menos meu problema é que eu esqueço. Muito. mais já estou escrevendo um pouco melhor porque muitas pessoas estão dizendo que eu melhorei na escrita já é um bom começo.Eu sei que pra mim é mais difícil por já esta numa idade avançada e muitos compromisso.

Mais não vou perde a Fé mais agradeço as PRF D e D.

O EJA para mim esta sendo muito importante para minha auto estima.

Aprendi varias matérias como música, ciências e matemática.

Eu estou aprendendo nas aulas de leitura e nas aulas de informática.

Esses relatos, de três alunos, que optamos por registrar do modo como escreveram na plataforma, apesar de conterem alguns erros de português, demonstram a riqueza de suas produções e o quanto a EJA estava fazendo diferença em suas trajetórias pessoais. Como destacou uma aluna: "A EJA para mim, está sendo muito importante para minha auto estima", ou ainda o aluno que sentia estar "escrevendo um pouco melhor", até porque, "muitas pessoas estão dizendo que melhorei na escrita". Assim como esses alunos, que já dominavam minimamente a leitura e a escrita, os alunos em fase inicial de alfabetização também fizeram o registro de seus avanços:

estou aprendendo DADO DIA MACACO MIMI OI EU IOIO

MARCELA BEBÊ BABÁ DADO AMANDA

A E I O U

CARLOS CARVALHO

DENISE

DIANA

MARCELA

$\mathrm{JOEL}^{4}$

Apesar de ainda não conseguirem escrever um texto sozinhos, incentivamos os sujeitos escolares a escreverem aquilo que já dominavam. Mesmo que pareça pouco a um primeiro olhar, além dos avanços no campo da alfabetização denotados pelas palavras grafadas na tela do computador, o simples fato de já saberem utilizar corretamente a tecla de espaço ao final de cada palavra escrita e a tecla "Enter" para mudar de linha ou o domínio do mouse nos garantiam que o trabalho que estávamos fazendo com a turma estava sendo produtivo.

Além das atividades que exploravam os recursos do Moodle, propusemos algumas atividades para os alunos que depois foram postadas por eles, com ajuda das docentes e do 
grupo de bolsistas que nos acompanhava. Entre essas atividades, uma delas foi bastante significativa para a turma, o que observamos a partir do retorno dos indivíduos. Em consonância ao trabalho pedagógico que estávamos desenvolvendo em sala de aula, ligado a um projeto sobre as origens de cada um, pedimos aos alunos que escrevessem os nomes de todos os lugares que lhes eram significativos, por onde já haviam passado em suas vidas. Após, foi solicitado que os estudantes pesquisassem na internet imagens desses lugares e salvassem essas imagens em um pen drive. Mais tarde, já de posse das imagens, cada aluno foi convidado a construir uma apresentação em PowerPoint para mostrar para os colegas e postar na sala de aula virtual.

Durante a construção das apresentações, cada aluno pôde dar seu toque pessoal, escolhendo as imagens que mais lhe agradavam, bem como as cores e o tipo de letra usado nos slides. Ao final, demonstravam muito orgulho de apresentar aos colegas o resultado de tanto esforço. Uma das alunas chamou uma das professoras ao final de sua apresentação com um pedido que não era incomum a cada atividade concluída: "Imprime pra mim, profe... quero mostrar para as minhas filhas e para os meus netos o que eu fiz!". Noutra atividade, cuja proposta era fazer cartazes sobre o racismo, na Semana da Consciência Negra, em que além das ferramentas de pesquisa, ensinamos o grupo a utilizar o Paint, imprimimos todos os cartazes, que ficaram expostos por algum tempo nos corredores da escola. No dia em que recolhemos essa produção, todos quiseram levar seu cartaz para casa para mostrar para os familiares. Sentíamos, em suas falas, que levar impresso o trabalho feito na aula de informática era uma forma de provar para todos que eles também sabiam usar o computador, que eles também podiam fazer parte desse mundo onde possuir conhecimentos tecnocientíficos faz toda diferença.

\section{Resultados}

Dentre os resultados da experiência que aqui apresentamos, observamos maior envolvimento e desenvoltura no uso dos computadores, com domínio parcial dos conceitos e ferramentas trabalhadas. O uso do Scala possibilitou aos estudantes envolvidos a criação de situações imaginativas ou contextuais, utilizando imagens e posteriormente a produção escrita. Tal iniciativa trouxe importantes contribuições para a aproximação dos estudantes com a informática, pois por se tratar de uma tecnologia assistiva, foi projetada para o fácil manuseio.

Os alunos que nas primeiras aulas tinham medo de tocar nos teclados dos computadores, ao final do ano já escolhiam sozinhos os jogos que queriam jogar dentre aqueles disponibilizados na plataforma Moodle pelas professoras, bem como clicavam em links de vídeos trabalhados para assistirem novamente. Observamos também que os alunos, ao final do segundo semestre, já dominavam o uso do mouse com maior destreza e demoravam menos tempo para digitar - mesmo aqueles em fase de alfabetização - pois estavam conseguindo localizar letras e pontuação no teclado.

Além dos resultados observados acerca dos progressos dos alunos no uso dos computadores, foi possível ver a satisfação dos mesmos ao conseguirem usufruir da internet via Wi-Fi disponibilizada pela universidade a qual é ligada a escola onde estudavam. Por termos inscrito a todos na rede da universidade, quando começamos a utilizar a plataforma Moodle, os alunos passaram a ter também acesso a internet via Wi-Fi em seus smartphones através de login e senha pessoais. Assim, por exemplo, após vários dias pedindo à professora titular da turma que "colocasse internet" no seu celular, um dos alunos acabou aprendendo a fazer esse processo sozinho e utilizava seu aparelho tanto nos intervalos das aulas, quanto durante as aulas, pesquisando dúvidas que surgiam durante as explicações. 
Nesses momentos, notávamos sua satisfação ao saber usar o próprio smartphone "sem precisar mais da ajuda dos filhos ou da professora."

\section{Considerações finais}

Portanto, aprender a usar o computador, o tablet, o smartphone, conhecer as inovações tecnológicas que surgem a cada dia e entender os efeitos disso na vida de todos e de cada um é tomado aqui como uma forma de inclusão social. O tipo de experiência que aqui descrevemos e analisamos, em que buscamos instrumentalizar alunos com pouca ou nenhuma vivência com o mundo da informática para o uso e discussão de recursos hoje disponíveis significa facilitar a participação do grupo de estudantes atendidos em debates e tomadas de decisões no campo tecnocientífico que lhes afetam diretamente. Como afirma Bensaude-Vincent (2013, p. 224), há a necessidade de que todos se envolvam nas escolhas científicas e tecnológicas. Para isso é necessário não apenas que os experts dialoguem com os "profanos", mas que as questões em discussão possam surgir das demandas dos segundos. Do mesmo modo, é importante que haja um processo de aprendizagem mútuo, em que diferentes pontos de vista, "profanos" e de experts sejam levados em consideração, o que muitas vezes pode levar a soluções não necessariamente tecnocientíficas. Uma terceira exigência levantada pela autora (BENSAUDE-VINCENT, 2013, p. 224)

[...] diz respeito ao envolvimento de um grande número de cidadãos e de grupos que não têm, normalmente, voz ativa em matéria de escolhas políticas. Com efeito, a participação do público no tratamento de questões tecnocientíficas é também uma forma de vulgarização do campo da ciência que é um processo de educação cívica. Além de um conhecimento profundo sobre o assunto, os cidadãos que se envolvem em painéis ou focus groups têm poder de agir (empowerment) e exercer seus direitos. Por fim, é essencial que essa cultura do debate participativo leve a consequências, ou seja, que leve a uma diferença no nível das tomadas de decisão, que ela desemboque num processo de admissão ou rejeição de inovações compartilhadas (grifo do autor).

Assim, podemos tomar as práticas descritas ao longo desse texto como uma forma de inserir mais sujeitos nos debates. Ao trazermos para estudantes que pouco ou nada dominavam da escrita e da leitura a vivência de uma ferramenta voltada para a produção de narrativas visuais, o uso de editores de textos e de imagens e mesmo a plataforma Moodle, nossa tentativa foi a de suscitar acontecimentos na educação. Acompanhando Gallo (2007, p. 100), suscitar acontecimentos na educação consistiria em "abrir-se para o que acontece, em sala de aula ou outros espaços escolares, para além do planejado, do planificado, dos objetivos definidos de antemão. Atentar mais para a trajetória do que para o ponto de chegada". Ainda há muito o que fazer. Não alcançamos o ponto de chegada, mas sentimo-nos honradas por estarmos tentando modificar trajetórias rumo a inclusão social.

\section{Referências}

AMPARO, Matheus Augusto Mendes. Informática na Educação de Jovens e Adultos: análise um programa de intervenção a favor da inclusão social e digital. 2015. 170 f. Dissertação (Mestrado em Educação) - Faculdade de Ciências e Tecnologia, Universidade Estadual Paulista Júlio de Mesquita Filho, Presidente Prudente, 2015.

BENDINELI, Lisandra Senra Avancini. A utilização da informática em aulas de matemática na EJA com colaboração de sequências didáticas. 2015. Dissertação (Mestrado em Educação em Ciências e Matemática) - Instituto Federal de Educação, Ciência e Tecnologia do Espírito Santo, Vitória, 2015. 
BENSAUDE-VINCENT, Bernadette. As vertigens da tecnociência: moldar o mundo átomo por átomo. São Paulo, SP: Idéias e Letras, 2013.

BOCASANTA, Daiane Martins. Dispositivo da tecnocientificidade: a Iniciação Científica ao alcance de todos. 2013. Tese (Doutorado em Educação) - Programa de Pós-Graduação em Educação, Universidade do Vale do Rio dos Sinos, São Leopoldo, 2013.

BOCASANTA, Daiane Martins; WANDERER, Fernanda; KNIJNIK, Gelsa. Educação de jovens e adultos e os conhecimentos tecnocientíficos: analisando as relações entre ciência, tecnologia e matemática. Horizontes, Itatiba, v. 34, n. 3, p. 81-92, dez. 2016. Disponível em: https://revistahorizontes.usf.edu.br/horizontes/article/view/349. Acesso em: 20 out. 2018.

BEZ, Maria Rosangela; PASSERINO, Liliana Maria (org.). Comunicação alternativa: mediação para inclusão social a partir do Scala. Passo Fundo: Editora da Universidade de Passo Fundo, 2015. Disponível em: http://editora.upf.br/images/ebook/Comunicao_alternativa_SCALA_PDF. pdf. Acesso em: 22 nov. 2018.

CANARIN, Gisele Joaquim. A organização curricular da Educação de Jovens e Adultos na modalidade EAD, na perspectiva da Educação Profissional Técnica de nível médio. 2013. Dissertação (Mestrado em Educação) - Universidade do Sul de Santa Catarina, Tubarão, 2013.

FOUCAULT, Michel. Microfísica do poder. Organização e tradução de Roberto Machado. Rio de Janeiro: Graal, 2008.

GALLO, Sílvio. Educação menor: produção de heterotopias no espaço escolar. In: RIBEIRO, Paula Regina Costa et al. (org.). Corpo, gênero e sexualidade: discutindo práticas educativas. Rio Grande: Editora da FURG, 2007. p. 93-102.

NOGUERA, Carlos. La Gubernamentalidad en Los Cursos del Profesor Foucault. Educação \& Realidade: revista da Faculdade de Educação da UFRGS, Porto Alegre, v. 34, n. 2, p. 21-34, maio/ ago. 2009. 